\title{
PET amyloid imaging as a tool for early diagnosis and identifying patients at risk for progression to Alzheimer's disease
}

\author{
Michael J Pontecorvo* and Mark A Mintun
}

\begin{abstract}
Current theory suggests that $\beta$-amyloid accumulation may be an early step in the cascade that leads to cognitive impairment in Alzheimer's disease. $\beta$-Amyloid targeted positron emission tomography (PET) imaging potentially provides a direct, relatively noninvasive estimate of brain $\beta$-amyloid burden. This has recently been supported by demonstration that amyloid plaque binding on PET was strongly correlated with brain $\beta$-amyloid burden at autopsy. Additionally, there is growing consensus that PET imaging can identify subjects with elevated $\beta$-amyloid burden, even at early stages of disease. Finally, preliminary evidence suggests that abnormal $\beta$-amyloid accumulation, as evidenced by PET imaging, has implications for both present and future cognitive performance. Although large longitudinal studies like the ongoing ADNI trial will be required for definitive evaluation, present data suggest that PET amyloid imaging has the potential to promote earlier and more specific diagnosis of dementia.
\end{abstract}

\section{Introduction}

The development in 1984 of consensus criteria [1] for diagnosis of Alzheimer's disease (AD) capped a period of evolving knowledge that $\mathrm{AD}$ could be differentiated not only from normal aging but also from other causes of neurodegenerative dementias. On average, clinical diagnosis using these consensus criteria is approximately $81 \%$ sensitive and $70 \%$ specific compared to the gold standard, pathology at autopsy [2], a performance that equals or exceeds the performance of proposed diagnostic criteria for many other neurodegenerative diseases $[2,3]$.

*Correspondence: pontecorvo@avidrp.com

Avid Radiopharmaceuticals, 3711 Market Street, $7^{\text {th }}$ Floor, Philadelphia, PA 19104, USA

BioMed Central o 2011 Biomed Central Ltd
Nevertheless, there remains both room and a need for improvement in diagnostic accuracy. Up to $20 \%$ of subjects clinically diagnosed with $\mathrm{AD}$ do not have $\mathrm{AD}$ pathology at autopsy [4-6], a percentage that is essentially unchanged from the estimate in the 1984 consensus publication [1]. In addition, under-diagnosis in the community setting is significant. Approximately $10 \%$ of community-dwelling elderly have undiagnosed dementia $[7,8]$ and community physicians may fail to diagnose up to $33 \%$ of individuals with mild dementia [8].

Perhaps the biggest limitation in current practice is a reliance on the presentation and progression of symptoms to identify an AD phenotype. This inherently leads to delays in diagnosis as physicians must wait for symptoms to appear and must track progressive decline over time. However, the past 25 years have seen dramatic improvements in technology and understanding of biomarkers that offer potential to improve this diagnostic algorithm. As a result, new draft criteria $[9,10]$ have proposed that diagnosis can be enhanced by use of biomarkers to increase certainty, and, in early stages, to identify prodromal AD. This approach has the potential to allow earlier and more specific diagnosis and will possibly identify patients with $\mathrm{AD}$ before the point where irreversible damage precludes effective treatment [11].

A number of different biomarkers, including atrophy on magnetic resonance imaging (MRI), regional metabolism as assessed by ${ }^{18} \mathrm{~F}$-fluorodeoxyglucose positron emission tomography (PET), and cerebrospinal fluid (CSF) concentrations of tau and $\beta$-amyloid $(A \beta)$ are potentially useful $[11,12]$, but molecular imaging with amyloid targeted PET ligands is a particularly attractive approach. Rate of atrophy on volumetric MRI and pattern of metabolic deficits on ${ }^{18} \mathrm{~F}$-fluorodeoxyglucose PET can provide useful information on stage of deterioration and functional status, but may lack specificity, since multiple types of neurologic disorders can cause the same type of changes [13-17]. CSF markers provide information (albeit indirect) more relevant to the underlying molecular pathology, including both $A \beta$ and tau, but require a relatively invasive procedure (lumbar puncture) and may 
not be entirely specific for $\mathrm{AD}$ [18]. In contrast, $A \beta$ imaging potentially provides a direct, relatively noninvasive estimate of brain $A \beta$ burden, which together with tau and a progressive pattern of neuronal loss is a defining pathology and an import link in the pathogenesis of $\operatorname{AD}[19,20]$.

The first, and to date most widely studied, ligand for PET imaging of $A \beta$ aggregates (subsequently referred to as amyloid PET or amyloid imaging) is the ${ }^{11} \mathrm{C}$-labeled agent known as Pittsburgh compound B (PIB) [21-23]. Although ${ }^{11} \mathrm{C}$-PIB has been a highly valuable tool in the research setting, the short (20-minute) half-life of the ${ }^{11} \mathrm{C}$ label limits the utility of ${ }^{11} \mathrm{C}$-PIB in routine clinical application. Thus, there has been a push to develop a longer lived ${ }^{18} \mathrm{~F}$-labeled amyloid PET agent. Three compounds are currently in the late stages of development. One of these, florbetapir F 18 [24-26] has now completed phase III trials [27], while florbetaben [28] and flutemetamol $[29,30]$ are currently enrolling to phase III trials.

The utility of PET amyloid imaging as an aid in early diagnosis rests on three major assumptions: first, that PET imaging accurately reflects $A \beta$ burden in the brain; second, that PET imaging can detect brain $A \beta$ at an early stage of disease, that is, prior to the onset of dementia; and finally, that the presence of $\beta$-amyloid, as detected by PET imaging, has consequences for current and future cognitive performance. We will examine the available evidence for each of these assumptions in turn.

\section{Relationship between PET amyloid imaging and brain $A \beta$ burden by histopathology}

In vitro studies have shown that PET imaging ligands such as ${ }^{11} \mathrm{C}$-PIB [21,31], florbetaben [32] and florbetapir F 18 [24] bind to $A \beta$ and co-localize with plaques stained by thioflavin and other amyloid labeling agents. However, a definitive demonstration of the relationship requires a comparison between in vivo imaging and brain pathology, for example, at autopsy.

Five single subject/single center PET to pathology comparison studies with ${ }^{11} \mathrm{C}$-PIB have produced mixed results. Two studies described patients with clinical diagnosis and autopsy confirmation of dementia with Lewy bodies (DLB) who had amyloid-positive ${ }^{11} \mathrm{C}$-PIB PET scans in life, and borderline $A \beta$ pathology at autopsy. Bacskai and colleagues [33] reported a visually positive ${ }^{11} \mathrm{C}-\mathrm{PIB}$ PET scan from a 76 year old with DLB and severe cerebral amyloid angiopathy. Regional quantification of the PET image, expressed as distribution volume ratio (DVR), revealed low to moderately elevated tracer levels (DVR $=1.3$ to 1.5 ), which was consistent with the autopsy findings of low to moderate levels of diffuse plaques and infrequent cored plaques (intermediate probability of $\mathrm{AD}$ by National Institute of Aging - Reagan Institute (NIAReagan) [34] criteria). However, there was no relationship across brain regions between regional DVR and regional levels of $A \beta 42$ in autopsy tissue as assessed by ELISA. Kantarci and colleagues [35] reported a positive ${ }^{11} \mathrm{C}$-PIB PET scan from a 77 year old with DLB. At autopsy neuritic plaques were moderately common in some brain regions, including mid-frontal gyrus, amygdale and superior parietal lobe, but sparse in the areas used for pathological diagnosis, resulting in an NIA-Reagan classification of low likelihood AD. In contrast to the previous study, there was a strong correlation between regional quantification of the PET image and regional $A \beta$ density by immunohistochemistry at autopsy. Two other reports studied subjects with a clinical diagnosis of AD. Ikonomovic and colleagues [31] reported an amyloid positive ${ }^{11} \mathrm{C}$-PIB PET scan in a 64 year old with severe AD. Strong correlations (0.7 to 0.8$)$ were seen between regional ${ }^{11} \mathrm{C}$-PIB PET tracer uptake (DVR) and various postmortem measures of $A \beta$ burden, including immunohistochemistry, histopathology and $\mathrm{A} \beta$ levels by ELISA. Cairns and colleagues [36] reported on a 91 year old with clinical diagnosis of early $\mathrm{AD}$ with a negative ${ }^{11} \mathrm{C}$-PIB PET scan but reduced CSF A $\beta$. The autopsy revealed numerous diffuse plaques, but sparse cored plaques and isolated neurofibrillary tangles (NFT). The neuropathologic diagnosis in this subject was borderline: low probability of AD by NIA-Reagan criteria, and possible AD by CERAD (Consortium to Establish a Registry for Alzheimer's Disease) criteria [37]. Additionally, the ${ }^{11} \mathrm{C}-$ PIB PET scan was taken more than 2 years prior to autopsy. Thus, it is difficult to determine whether this case should be considered a failure of the ${ }^{11} \mathrm{C}$-PIB PET scan to detect an early stage of $\mathrm{AD}$, or a successful rejection of a case that lacked convincing $\mathrm{AD}$ pathology. Finally, Leinonen and colleagues [38] reported that five of ten subjects who had a tissue removed for a shunt for normal pressure hydrocephalis had significant numbers of $\mathrm{A} \beta$ aggregates by immunohistochemistry at biopsy. Four of these subjects had abnormal ${ }^{11} \mathrm{C}$-PIB PET scans (elevated cortex to cerebellum standard uptake volume ratio (SUVR)). The overall correlation between SUVR and number of amyloid aggregates across the ten subjects was 0.85 .

Clark and colleagues [27] recently reported the first prospective multicenter phase III study to evaluate the correlation between the level of cortical amyloid burden on PET scan and true A $\beta$ burden assessed by postmortem histopathology. In this study, 152 subjects with cognitive status ranging from cognitively normal to mild cognitive impairment $(\mathrm{MCI})$ to $\mathrm{AD}$ or other dementing disorders agreed to both florbetapir-PET scan and subsequent autopsy. As specified by the protocol, the first six subjects to come to autopsy were considered front runners and were used to confirm the experimental methods, and the next 29 subjects to come to autopsy were considered the 
primary efficacy population. Cortical amyloid burden on florbetapir-PET scans was visually assessed on a 0-to-4 scale (no-to-high cortical tracer uptake) by three independent raters, blinded to clinical information, with the median rater score as the primary outcome variable, and by a semi-automated quantification of the SUVR in six cortical target areas (frontal, temporal and parietal cortex, precuneus, anterior and posterior cingulate) relative to the cerebellum reference region. Amyloid burden at autopsy was assessed by quantitative immunohistochemistry (primary outcome variable) and by a modified CERAD scoring (silver stain) in the six cortical target regions. The results showed a strong, statistically significant correlation between the level of cortical tracer uptake in the PET image, whether assessed by median visual read or SUVR, and true A $\beta$ burden, whether assessed postmortem by quantitative immunohistochemistry or silver stain $(\rho=0.71$ to $0.78, P<0.0001)$. Similar results were obtained in the primary efficacy set $(n=29)$ and in the entire autopsy data set $(n=35$, including the front runners). There was qualitative agreement between florbetapir-PET and postmortem results in $97 \%$ of the autopsied subjects. Of 19 subjects that met pathologic criteria (CERAD and NIA-Reagan) for AD, 18 were rated visually positive for amyloid by median read, and all 19 had SUVR above a predefined cutpoint. Conversely, all 16 subjects that did not meet pathologic criteria (amyloid free) at autopsy were amyloid free by both visual and quantitative analysis of the PET scan.

Although the data with ${ }^{11} \mathrm{C}$-PIB are somewhat limited, the results with florbetapir F 18 provide a strong preliminary indication that PET amyloid imaging can provide an accurate reflection of underlying $A \beta$ burden. However, further studies are required to understand how early in the disease course the amyloid pathology can be detected. In both the ${ }^{11} \mathrm{C}$-PIB $[36,38]$ and florbetapir F 18 [27] studies there were some subjects with measurable but low levels of amyloid pathology at autopsy that were not associated with amyloid-positive PET scans. In most cases, the level of pathology in these patients at autopsy was below the threshold for neuropathological diagnosis of $\mathrm{AD}$ (that is, rated low likelihood or no AD). Thus, the threshold for detection of amyloid on the PET scan appears close to the levels of neuropathology typical for a diagnosis of AD. It is presently unclear whether levels of $\mathrm{A} \beta$ burden at autopsy that are insufficient to be thought of as $\mathrm{AD}$ actually represent an early stage of disease $[35,36]$, or whether they represent variants of amyloid deposition, including normal aging [39]. Longitudinal studies, with periodic repeat scans and cognitive testing, would be useful to determine how much or for how long a negative scan in a cognitively normal individual reduces risk of future amyloid accumulation and cognitive impairment. Such studies are now starting as part of the second phase Alzheimer's Disease Neuroimaging Initiative (ADNI; for example, ADNI-2) protocol [40].

On the other hand, across both the ${ }^{11} \mathrm{C}$-PIB and the florbetapir F 18 image/autopsy studies there were no cases in which a positive amyloid PET scan was obtained in a subject found to be cognitively normal and amyloid free at autopsy. These results suggest that there is a high probability of underlying brain $A \beta$ pathology in subjects with positive amyloid PET scans. This kind of high specificity and positive predictive value, compared to the autopsy gold standard, is a prerequisite for a biomarker to be used as an aid to early diagnosis of dementia.

\section{Early detection of amyloid by PET imaging in MCI and cognitively normal subjects}

Current theories of $\mathrm{AD}$ pathophysiology hold that $\mathrm{A} \beta$ deposition may be a precipitating event that begins years in advance of the onset of dementia [41-43]. Evidence in support of the hypothesis includes the finding that $15 \%$ or more of cognitively normal subjects coming to autopsy may have plaque burden sufficient to support a diagnosis of $\mathrm{AD}$ [44-46] and 33 to $62 \%$ of subjects with MCI have significant accumulation of $\mathrm{A} \beta$ plaques $[47,48]$. Corresponding changes in biomarkers have also been reported in non-demented individuals. Notably, studies of CSF biomarkers have consistently shown decreases in CSF A $\beta$ in 30 to $40 \%$ of cognitively normal subjects [49,50]. Changes in CSF tau, MRI volume and cerebral metabolism may occur slightly later than changes in CSF A $\beta$ $[41,49,51]$.

Amyloid PET imaging studies have yielded results similar to those from autopsy and CSF studies. Studies using ${ }^{11} \mathrm{C}$-PIB have reported amyloid-positive scans in 14 to $47 \%$ of cognitively normal elderly volunteers $[40,43$, 52-55], and 55 to $72 \%$ of subjects with MCI [51,54-57]. Where data from both ${ }^{11} \mathrm{C}$-PIB PET scans and CSF $\mathrm{A} \beta$ have been available, strong correlations between these measures have generally been reported [49,57]. Results with ${ }^{18} \mathrm{~F}$-labeled imaging agents are similar to those for ${ }^{11} \mathrm{C}$-PIB. The proportion of $\mathrm{A} \beta$-positive scans in cognitively normal subjects has ranged from $7 \%$ and $12 \%$ with flutametamol [29,30], to $13 \%$ with florbetapir [26], and $20 \%$ with florbetaben [28]. In MCI subjects the proportion of positive scans was about $50 \%$ for flutametamol [30] and florbetaben [58] and about $38 \%$ in the studies with florbetapir [59].

The differences across PET studies, which are similar to the differences in the pathological studies of cognitively normal controls and $\mathrm{MCI}$, could easily be related to differences in subject age and inclusion criteria rather than differences in sensitivity of the different tracers. Consistent with findings in the autopsy literature [45,60], the proportion of cognitively healthy control subjects that are $A \beta$-positive by PET scan increases with age 
$[26,30,44,49,53]$. The mean age of cognitively healthy subjects varied by more than 10 years across the studies above $[29,55]$. Additionally, the florbetapir trial [58] was designed to evaluate early stage MCI patients, diagnosed within the past year. These subjects may be more difficult to diagnose and thus more heterogeneous, leading to inclusion of a greater number of subjects with nonamyloid/AD-related impairments.

Jagust and colleagues [40], reporting on ${ }^{11} \mathrm{C}$-PIB subjects from the ADNI study, further evaluated quantitative values (cortical to cerebellar SUVR) for the $A \beta$-positive and $A \beta$-negative subjects by diagnostic presentation group (cognitively healthy, $\mathrm{MCI}$ and $\mathrm{AD}$ ). Interestingly, there was no apparent difference in SUVR between A $\beta$ positive MCI and $A \beta$-positive AD, but SUVR in $A \beta$ positive $\mathrm{MCI}$ and $\mathrm{AD}$ both appeared greater than SUVR in $\mathrm{A} \beta$-positive healthy controls. These results are consistent with histopathology findings [47], indicating that the relative proportion of patients with high versus moderate levels of $A \beta$ pathology at autopsy (definite versus probable AD by CERAD criteria) does not increase from $\mathrm{MCI}$ to $\mathrm{AD}$ patients, and suggests that $\mathrm{A} \beta$ accumulation reaches asymptote at early stages of disease.

Together with the image-autopsy results described above [27], these results suggest that PET imaging can detect the presence of $A \beta$ aggregates sufficient to support a pathological diagnosis of AD in upwards of $15 \%$ of cognitively healthy elderly subjects (prevalence increasing with age) as well as in 40 to $70 \%$ of subjects with MCI. Thus, the results are consistent with the hypothesis [41] that PET amyloid imaging can detect $A \beta$ accumulation well in advance of the onset of dementia. The next section will consider the available literature regarding consequences of a positive amyloid scan for present and future cognitive performance in cognitively healthy and $\mathrm{MCI}$ subjects.

\section{Relationship between amyloid PET imaging and cognitive performance/progression}

The most obvious prediction from the model of Jack and colleagues [41] is that compared to subjects who have a negative amyloid PET scan, cognitively healthy control and MCI subjects who have positive amyloid PET scans will, as a group, show greater deterioration in cognitive performance, and will be more likely to progress to an advanced stage of disease (for example, from MCI to AD). A significant number of studies have looked at the relationship between PET amyloid binding and concurrent cognitive performance. Multiple studies have reported no correlation between amyloid binding and degree of cognitive deficits in AD patients $[55,61,62]$. This is consistent with the hypothesis that amyloid is an early initiating event in a pathological cascade, that $A \beta$ accumulation approaches asymptote by the time that symptoms appear, and that other pathological processes (tau phosphorylation, inflammation, synaptic degeneration) are more closely linked to expression of cognitive impairment in AD patients [41].

Results are more mixed for MCI subjects. Pike and colleagues [55] found a good correlation $(r=0.61)$ between ${ }^{11} \mathrm{C}$-PIB SUVR and a working memory composite score. Others have found no consistent differences in cognition as a function of PET amyloid imaging [43,54]. However, it is likely that correlational studies in MCI subjects are particularly sensitive to the diagnostic algorithms used to select and define MCI subjects. Overlap between the diagnostic algorithm and cognitive outcome variables can reduce the chances of finding a relationship between an independent variable and cognitive performance; for example, if all subjects must have objectively demonstrated memory deficits for inclusion in the study cohort, it becomes difficult to demonstrate a relationship between amyloid burden and memory performance within the cohort. Additionally, as noted above, amyloid levels may approach asymptote by the MCI stage, and differences in brain amyloid burden beyond that point may have as much to do with modulating factors influencing the individual subject's asymptotic level as they do with disease stage.

In cognitively healthy elderly subjects, Mintun and colleagues [52], Storandt and colleagues [62] and Jack and colleagues [54] reported no relationship between concurrent cognitive performance and ${ }^{11} \mathrm{C}$-PIB amyloid binding. Other studies have found mixed results. Mormimo and colleagues [63] reported a relationship between ${ }^{11} \mathrm{C}$-PIB amyloid binding and episodic memory for one population of normal elderly, but not for a second population. Rowe and colleagues [43] reported that subjects with high PIB amyloid binding had significantly reduced memory scores relative to subjects with low amyloid binding, but the correlation between binding and memory was not significant. In contrast, several studies $[55,64,65]$ have now reported correlations between ${ }^{11} \mathrm{C}$-PIB amyloid binding and memory scores. Similarly, Rosenberg and colleagues [61] examined cognitive performance in the cohort of subjects described by Wong and colleagues [26] and found a significant correlation between florbetapir F 18 binding and ADAS-cog (Alzheimer's Disease Assessment Scale Cognitive Subscale) performance by normal elderly controls. Park and colleagues [66] have also recently reported a relationship between florbetapir PET amyloid binding and working memory performance in cognitively normal aging subjects.

It is not surprising that the strength of correlation between PET result and cognitive performance, and/or the magnitude of the difference in cognitive performance between cognitively normal subjects with $A \beta$-positive and $A \beta$-negative PET scans, was modest and sometimes 
variable. At least three factors work to limit the magnitude of effect that can be obtained in cognitively normal subjects. First, the range of cognitive performance in cognitively normal subjects is constrained by the criteria used to separate cognitively impaired subjects from cognitively normal. The earlier and more aggressively the diagnosis of impairment is made, the less potential for variance within the normal group as a function of amyloid level, as subjects with greater amyloid burden, and more advanced impairment, may be classified as cognitively impaired. Second, the outcome may depend on the difficulty of the cognitive tests used. More difficult tests are more likely to uncover deficits that may otherwise go unnoticed [64]. Finally, the relationship between amyloid binding and cognitive performance can be modified by the subject's education/ cognitive reserve $[64,65]$. Subjects with high education/ high cognitive reserve appear to maintain cognitive function in the normal range for a longer period or in the face of greater PET amyloid binding than subjects with lower cognitive reserve.

The Pike and colleagues [55] and the Rentz and colleagues [64] reports above both include scatterplots of cognitive performance as a function of amyloid binding (SUVR). Rather than a preferential distribution of abnormally low memory scores in association with high amyloid binding, the scatterplots are notable for the relative absence of high memory scores in the high amyloid group. It is tempting to speculate that this kind of distribution is the result of the limiting factors discussed above. In the amyloid-positive cohort, subjects with low cognitive reserve cannot sustain performance and become classified as MCI, whereas subjects with high cognitive reserve, who otherwise would have been above average memory performers, have deteriorated but are still performing near the middle of the normal range. However, this kind of hypothesis can only be addressed by longitudinal studies.

The relationship between amyloid burden as assessed by PET imaging and longitudinal change in cognitive function in cognitively normal and MCI populations is currently under examination in multiple trials, including the US ADNI study [40] $\left({ }^{11} \mathrm{C}\right.$-PIB, phase 1 , and florbetapir F 18, phase 2), the Australian Imaging, Biomarkers and Lifestyle Initiative (AIBL) initiative [43] $\left({ }^{11} \mathrm{C}\right.$-PIB) and several ongoing longitudinal trials of aging [62,67], as well as in several trials with ${ }^{18} \mathrm{~F}$-labeled agents that are either still ongoing (flutemetamol, NCT01028053; florbetaben, NCT01138111; ClinicalTrials.gov) or recently completed (florbetapir) [59]. First results, now coming into the literature, strongly suggest a relationship between amyloid burden and AD progression.

Four published studies have examined the potential of ${ }^{11} \mathrm{C}-\mathrm{PIB}$ PET amyloid imaging to predict progression from MCI to AD. Forsberg and colleagues [57] imaged 27 MCI subjects and reported that 7 who subsequently converted to $\mathrm{AD}$ had higher $\mathrm{PIB}$ retention than nonconverting subjects. Okello and colleagues [56] studied 31 MCI subjects, 17 (55\%) of whom were considered amyloid-positive on an ${ }^{11} \mathrm{C}$-PIB PET scan. Of these 17 subjects, $14(82 \%)$ converted from $\mathrm{MCI}$ to $\mathrm{AD}$ in the follow-up period (up to 3 years). Only 1 of 14 (7\%) amyloid-negative subjects converted in the same time period. A comparison of fast $(<1$ year) versus slower converters suggested that fast converters (within one year of scan; 8 of 17 amyloid-positive subjects) had higher ${ }^{11} \mathrm{C}$-PIB PET cortical to cerebellar uptake ratios than the slower converters, despite a similar mean age. Notably, all fast converters for whom genotype was available carried an apolipoprotein E \&4 alleole, whereas only two of six slow converters with genotype information carried an apolipoprotein E $\varepsilon 4$ alleole. Thus, the $\varepsilon 4$ alleole may have contributed to both the elevated amyloid burden (increased SUVR) and the more rapid conversion. Wolk and colleagues [68] similarly reported a higher rate of conversion in subjects classified as amyloid-positive (5 of $13,38 \%$ ) versus amyloid-negative (zero of 10 ) by ${ }^{11} \mathrm{C}$-PIB PET. Finally, Jack and colleagues [69] recently published the first report of follow-up results from the ADNI study. Of $218 \mathrm{MCI}$ subjects included in the analysis, ${ }^{11} \mathrm{C}$-PIB data were available for 53 subjects, and CSF A $\beta$ levels, but not ${ }^{11} \mathrm{C}$-PIB, were available for 165 . In order to increase power and to better draw conclusions regarding relationships between amyloid burden and disease progression, CSF data from subjects who did not undergo ${ }^{11} \mathrm{C}$-PIB imaging were transformed to facilitate a combined quantitative analysis. Over the observation period, 81 of 165 amyloid-positive versus 8 of 53 amyloid-negative MCI subjects progressed to AD. A Kaplin Meyer analysis estimated a significantly increased hazard ratio (3.2) with a 2 -year estimated conversion rate of $50 \%$ in the amyloidpositive versus $19 \%$ in the amyloid-negative subjects.

Only one study has reported progression of cognitively normal subjects to more advanced disease. Morris and colleagues [70] performed ${ }^{11} \mathrm{C}$-PIB scans in 159 cognitively normal (Clinical Dementia Rating (CDR) 0) subjects that were part of a longitudinal aging study and reported that the relative risk of conversion from CDR 0 to $\mathrm{AD}$ (nine subjects) was increased almost five-fold in the presence of a positive ${ }^{11} \mathrm{C}$-PIB amyloid scan. A lesser, non-significant increase in risk was reported for conversion from CDR 0 to CDR $0.5(n=23)$.

The primary weakness of studies using conversion/ stage change as an endpoint is that the rate of conversion, particularly from healthy to MCI or AD, may be low and variable across subjects and studies, depending on recruiting centers and entry criteria. Hence, three studies in cognitively normal aging elderly have looked instead at 
the relationship between PET amyloid binding and continuous measures, that is, change in objectively measured cognitive performance. Storandt and colleagues [62], working with essentially the same subject population as Morris and colleagues [70], found that concurrent cognitive performance was unrelated to ${ }^{11} \mathrm{C}$-PIB binding, but the estimated annual rate of cognitive deterioration, as evidenced by change in visuospatial and working memory performance composite scores, was significantly greater in subjects with an amyloid-positive ${ }^{11}$ C-PIB PET scan than in subjects with an amyloid-negative ${ }^{11} \mathrm{C}$-PIB scan. High amyloid binding on ${ }^{11} \mathrm{C}$-PIB scans was also associated with reduced regional brain volume on MRI, further suggesting that even in cognitively normal subjects (CDR 0) amyloid accumulation is not benign. Villemagne and colleagues [71] imaged 34 elderly subjects that had been previously followed longitudinally for 6 to 10 years. On average, subjects with memory decline over the observation period had higher ${ }^{11} \mathrm{C}$-PIB retention; 7 of 11 subjects with elevated ${ }^{11} \mathrm{C}$-PIB retention showed memory decline, versus 4 of 23 subjects with normal ${ }^{11} \mathrm{C}$-PIB retention. Finally, Resnick and colleagues [67] obtained ${ }^{11} \mathrm{C}$-PIB PET images on 57 subjects who had been followed for an average of 10.8 years as part of the Baltimore Longitudinal Study of Aging and found a significant correlation between ${ }^{11} \mathrm{C}$-PIB binding (DVR) and Mini Mental State Exam and verbal memory (California Verbal Learning Test).

One weakness of the Storandt and colleagues [62], Villemagne and colleagues [71] and Resnick and colleagues [67] studies is that they rely primarily on retrospective analysis of cognitive decline. Although several groups have now reported that change in ${ }^{11} \mathrm{C}$-PIB binding is relatively slow, particularly in amyloid-positive subjects $[40,51]$, it is difficult to judge from a retrospective analysis how early the ${ }^{11} \mathrm{C}$-PIB PET could have predicted subjects likely to show cognitive decline. Of course, these groups and others (for example, ADNI) are now following subjects prospectively from the point of imaging. One recent preliminary report [59] was consistent with the results above showing a relationship between florbetapir PET amyloid binding and prospectively measured cognitive decline.

In summary, the data to date are limited, but taken together provide evidence that abnormal accumulation of $\mathrm{A} \beta$ as evidenced by PET amyloid imaging is associated with increased risk of both concurrent cognitive deficits and subsequent progression of cognitive impairment, and thus may be pathological even in apparently cognitively normal subjects.

\section{Conclusion}

Emerging consensus regarding diagnostic algorithms and criteria suggests that diagnosis of AD can be enhanced by use of biomarkers to increase certainty, and, in early stages, to identify the group of patients at risk for progression to $\mathrm{AD}$. The data reviewed above suggest that PET amyloid imaging may be well suited to both tasks. Amyloid binding on PET has been shown to be strongly correlated with brain A $\beta$ burden at autopsy, and PET imaging identified amyloid-positive subjects with a high sensitivity and specificity in relationship to postmortem histopathological criteria for AD. Additionally, there is consistent evidence that PET imaging can identify subjects with elevated $A \beta$ burden, even at early stages of disease, and preliminary evidence suggests that excess $A \beta$ accumulation, as evidenced by PET imaging, has implications for both present and future cognitive performance.

Current theory suggests that $A \beta$ accumulation may be a critical early step in a cascade of events, including phosphoryl tau and inflammation-mediated synaptic damage and neuronal loss, that leads to cognitive impairment in AD. Early identification of subjects with $A \beta$ accumulation may be critical to the development of potential disease-modifying therapies because amyloid targeted therapies may not be effective once later stages of the cascade have begun.

There is an opportunity to identify patients earlier than occurs in current clinical practice. Typical patients in clinical trials, who are generally well educated and well integrated into the medical system, report delays of approximately 2 years between symptom onset and diagnosis. Delays may be even greater in a community setting where physicians are known to overlook diagnoses in a substantial proportion of patients. However, improved diagnostic aids, such as amyloid-targeted PET scans, alone may not be sufficient to overcome this problem. Diagnostic delays may be partly a matter of patient education (recognition and acceptance of $\mathrm{AD}$ symptoms, readiness to seek treatment) and physician practice. In particular, some physicians may be unwilling to commit to diagnosis in the absence of viable treatments. On the other hand, tools that provide evidence of the underlying pathology might improve physician's confidence, and lead to an earlier diagnosis, by reducing the need for longitudinal follow-up and progression to a more advanced stage of symptoms. Equally important, the evidence indicates that PET amyloid scans can identify patients with early cognitive impairments who do not have pathological levels of brain $A \beta$ at autopsy. Since $A \beta$ pathology is required for a diagnosis of $A D$, the early demonstration of the absence of $A \beta$ may lead instead to further evaluation of potentially treatable causes of impairment (for example, depression) in these patients.

When, and in what population of patients, should amyloid PET imaging be used? It is easy enough to identify and rule out the extremes. On the one extreme, a 
well characterized patient whose disease has progressed beyond the point where a scan would influence medical management would likely derive little benefit from a PET scan. On the other extreme the evidence to date is not sufficient to support routine use in screening cognitively normal subjects, even in the presence of risk factors. Although the results discussed above (for example, $[55,61])$ suggest that subjects who are amyloid-positive on PET scan may perform worse on cognitive tests, the results have not been entirely consistent across trials, and the effects are subtle and of uncertain clinical relevance. Most important, too few amyloid-positive subjects have been identified and followed longitudinally to give guidance to the patient regarding likelihood and time course of future cognitive deterioration. Current estimates of 10 years or more between the first signs of excess $A \beta$ accumulation and onset of dementia suggest that many amyloid-positive elderly patients might pass on before experiencing significant cognitive decline.

In between these extremes lie a large number of patients that could potentially benefit from PET amyloid scans. With three ${ }^{18} \mathrm{~F}$-labeled amyloid targeted ligands having entered or already completed phase III trials, it is likely that amyloid PET scans will be broadly available within the next few years. Additional studies and consensus evaluations are needed to determine the best use for these agents. Despite the positive results described above, it is clear that an amyloid PET scan is not sufficient to confer a diagnosis of $\mathrm{AD}$. $\mathrm{A} \beta$ can be present in association with other disease conditions, including DLB, Parkinson's disease and cerebrovascular disease. It remains unclear whether this reflects the coincidence of two or more disease entities (for example, AD independently in addition to DLB) or whether $A \beta$ (and tau) pathology can be found independently in multiple disease entities.

In either case, the advent of PET amyloid imaging techniques does not obviate the need for clinical/cognitive evaluation. Moreover, the information obtained from amyloid PET imaging may be enhanced by additional biomarker studies, including, for example, functional imaging [72], or molecular imaging aimed at dopamine systems [73-75]. Additional studies are required to identify which patients most benefit from PET amyloid imaging and which additional diagnostic assessments are most useful in developing a practice parameter to optimize the potential for early evaluation of cognitive impairment.

This article is part of a review series on Amyloid Imaging. Other articles in the series can be found online at http://alzres.com/series/ amyloidimaging

\section{Abbreviations}

$A \beta, \beta$-amyloid; AD, Alzheimer's disease; ADNI, Alzheimer's Disease Neuroimaging Initiative; CDR, Clinical Dementia Rating; CERAD, Consortium to Establish a Registry for Alzheimer's Disease; CSF, cerebral spinal fluid; DLB, dementia with Lewy bodies; DVR, distribution volume ratio; ELISA, enzymelinked immunosorbent assay; FDG, ${ }^{18}$ F-fluorodeoxyglucose; $\mathrm{MCl}$, mild cognitive impairment; MRI, magnetic resonance imaging; NFT, neurofibrillary tangles; NIA-Reagan, National Institute of Aging - Reagan Institute; PET, positron emission tomography; PIB, Pittsburgh compound B; SUVR, standard uptake volume ratio.

\section{Competing interests}

MP and MM are employees and stockholders in Avid Radiopharmaceuticals. Avid owns the patent license for florbetapir F 18, one of the PET amyloid

imaging compounds discussed in this review.

\section{Authors' contributions}

Both MP and MM contributed to the analysis and views expressed in this review. MP drafted the manuscript with critical revision by MM.

\section{Acknowledgements}

The authors would like to thank Drs Alan Carpenter, Christopher Clark, Franz Hefti and Daniel Skovronsky for discussions that shaped the ideas expressed in this review, and Dr Reisa Sperling for comments on a preliminary draft.

\section{Published: 29 March 2011}

\section{References}

1. McKhann G, Drachman D, Folstein M, Katzman R, Price D, Stadlan EM: Clinical diagnosis of Alzheimer's disease: Report of the NINCDS-ADRDA Work Group under the auspices of Department of Health and Human Services Task Force on Alzheimer's Disease. Neurology 1984, 34:939-944.

2. Knopman DS, DeKosky ST, Cummings JL, Corey-Bloom J, Relkin N, Small GW, Miller B, Stevens JC: Practice parameter: Diagnosis of dementia (An evidence-based review). Neurology 2001, 56:1143-1153.

3. McKeith I, Mintzer J, Aarsland D, Burn D, Chiu H, Cohen-Mansfield J, Dickson D, Dubois B, Duda JE, Feldman H, Gauthier S, Halliday G, Lawlor B, Lippa C, Lopez OL, Machado JC, O'Brien J, Playfer J, Reid W: Dementia with Lewy bodies. Lancet Neurol 2004, 3:19-28.

4. Lim A, Tsuang D, Kukull W, Nochlin D, Leverenz J, McCormick W, Bowen J, Teri L, Thompson J, Peskind ER, Raskind M, Larson ER: Clinico-neuropathological correlation of Alzheimer's disease in a community-based case series. J Am Geriatr Soc 1999, 47:564-569.

5. Mayeux R, Saunders AM, Shea S, Mirra S, Evans D, Roses AD, Hyman BT, Crain $B$, Tang MX, Phelps CH: Utility of the apolipoprotein E genotype in the diagnosis of Alzheimer's disease. Alzheimer's Disease Centers Consortium on Apolipoprotein E and Alzheimer's Disease. N Eng/ J Med 1998, 338:506-511.

6. Ranginwala NA, Hynan LS, Weiner MF, White CL III: Clinical criteria for the diagnosis of Alzheimer disease: still good after all these years. Am J Geriatr Psychiatry 2008, 16:384-388.

7. Solomon PR, Brush M, Calvo V, Adams F, DeVeaux RD, Pendlebury WW, Sullivan DM: Identifying dementia in the primary care practice. Int Psychogeriatr 2000, 12:483-493.

8. Löppönen M, Räihä I, Isoaho R, Vahlberg T, Kivelä SL: Diagnosing cognitive impairment and dementia in primary health care - a more active approach is needed. Age Ageing 2003, 32:606-612.

9. McKhann GM, Knopman DS, Chertkow H, Hyman BT, Jack CR, Kawas CH, Klunk WE, Koroshetz WJ, Manly JJ, Mayeux R, Mohs RC, Morris JC, Rossor MN, Scheltens P, Thies W, Weintraub S, Phelps CH: The diagnosis of dementia due to Alzheimer's disease: recommendations from the National Institute on Aging and the Alzheimer's Association Workgroup. Alzheimers Dement 2011, in press.

10. Albert, MS, DeKosky ST, Dickson D, Dubois B, Feldman HH, Fox NC, Gamst A, Holtzman DM, Jagust WJ, Petersen, RC, Snyder PJ, Phelps CH: The diagnosis of mild cognitive impairment due to Alzheimer's Disease: Recommendations from the National Institute on Aging and Alzheimer's Association Workgroup. Alzheimers Dement 2011, in press.

11. Dubois B, Feldman HH, Jacova C, Dekosky ST, Barberger-Gateau P, Cummings J, Delacourte A, Galasko D, Gauthier S, Jicha G, Meguro K, O'brien J, Pasquier F, Robert P, Rossor M, Salloway S, Stern Y, Visser PJ, Scheltens P: Research criteria 
for the diagnosis of Alzheimer's disease: revising the NINCDS-ADRDA criteria. Lancet Neurol 2007, 6:734-746

12. Thal $\sqcup$, Kantarci K, Reiman EM, KlunkWE, Weiner MW, Zetterberg H, Galasko $D$, Praticò D, Griffin S, Schenk D, Siemers E: The role of biomarkers in clinical trials for Alzheimer disease. Alzheimer Dis Assoc Disord 2006, 20:6-15.

13. de Leon MJ, Mosconi L, Blennow K, DeSanti S, Zinkowski R, Mehta PD, Pratico D, Tsui W, Saint Louis LA, Sobanska L, Brys M, Li Y, Rich K, Rinne J, Rusinek H: Imaging and CSF studies in the preclinical diagnosis of Alzheimer's disease. Ann N Y Acad Sci 2007, 1097:114-145.

14. Frey KA, Minoshima S, Kuhl DE: Neurochemical imaging of Alzheimer's disease and other degenerative dementias. Q J Nucl Med 1998, 42:166-178.

15. Hoffman JM, Welsh-Bohmer KA, Hanson M, Crain B, Hulette C, Earl N, Coleman RE: FDG PET imaging in patients with pathologically verified dementia. J Nucl Med 2000, 41:1920-1928.

16. Minoshima S: Imaging Alzheimer's disease: Clinical applications. Neuroimaging Clin N Am 2004, 13:769-80.

17. Silverman DH, Small GW, Chang CY, Lu CS, Kung De Aburto MA, Chen W, Czernin J, Rapoport SI, Pietrini P, Alexander GE, Schapiro MB, Jagust WJ, Hoffman JM, Welsh-Bohmer KA, Alavi A, Clark CM, Salmon E, de Leon MJ, Mielke R, Cummings JL, Kowell AP, Gambhir SS, Hoh CK, Phelps ME: Positron emission tomography in evaluation of dementia: Regional brain metabolism and long-term outcome. JAMA 2001, 286:2120-2127.

18. Craig-Schapiro R, Fagan AM, Holtzman DM: Biomarkers of Alzheimer's disease. Neurobiol Dis 2009, 35:128-140.

19. Mirra SS, Heyman A, McKeel D, Sumi SM, Crain BJ, Brownlee LM, Vogel FS, Hughes JP, van Belle G, Berg, L: The Consortium to Establish a Registry for Alzheimer's Disease (CERAD). Part II. Standardization of the neuropathologic assessment of Alzheimer's disease. Neurology 1991, 41:479-486.

20. Hyman BT, Trojanowski JQ: Consensus recommendations for the postmortem diagnosis of Alzheimer disease from the National Institute on Aging and the Reagan Institute Working Group on diagnostic criteria for the neuropathological assessment of Alzheimer disease. J Neuropathol Exp Neurol 1997, 56:1095-1097

21. Klunk WE, Wang Y, Huang GF, Debnath ML, Holt DP, Mathis CA: Uncharged thioflavin-T derivatives bind to amyloid-beta protein with high affinity and readily enter the brain. Life Sci 2001, 69:1471-1484.

22. Klunk WE, Engler H, Nordberg A, Wang Y, Blomqvist G, Holt DP, Bergström $M$, Savitcheva I, Huang GF, Estrada S, Ausén B, Debnath ML, Barletta J, Price JC, Sandell J, Lopresti BJ, Wall A, Koivisto P, Antoni G, Mathis CA, Långström B: Imaging brain amyloid in Alzheimer's disease with Pittsburgh CompoundB. Ann Neurol 2004, 55:306-319.

23. Klunk WE, Lopresti BJ, Ikonomovic MD, Lefterov IM, Koldamova RP, Abrahamson EE, Debnath ML, Holt DP, Huang GF, Shao L, DeKosky ST, Price $J C$, and Mathis $C A$ : Binding of the positron emission tomography tracer Pittsburgh Compound-B reflects the amount of amyloid- $\beta$ in Alzheimer's disease brain but not in transgenic mouse brain. J Neurosci 2005, 25:10598-10606.

24. Choi SR, Golding G, Zhuang Z, Zhang W, Lim N, Hefti F, Benedum TE, Kilbourn MR, Skovronsky D, Kung HF: Preclinical properties of ${ }^{18} \mathrm{~F}-\mathrm{AV}-45$ : A PET agent for A $\beta$ plaques in the brain. J Nucl Med 2009, 50:1887-1894.

25. Lin KJ, Hsu WC, Hsiao IT, Wey SP, Jine LW, Skovronsky D, Waia YY, Changa HP, Loa CW, Yaoa CH,Yen TC, Kung MP: Whole-body biodistribution and brain PET imaging with [18F]AV-45, a novel amyloid imaging agent - a pilot study. Nucl Med Biol 2010, 37:497-508

26. Wong DF, Rosenberg PB, Zhou Y, Kumar A, Raymont V, Ravert HT, Dannals RF, Nandi A, Brasic JR, YeW, Hilton J, Lyketsos C, Kung HF, Joshi AD, Skovronsky DM, Pontecorvo MJ: In vivo imaging of amyloid deposition in Alzheimer disease using the radioligand ${ }^{18} \mathrm{~F}-\mathrm{AV}-45$ (florbetapir F 18). J Nucl Med 2010 51:913-920.

27. Clark CM, Schneider JA, Mintun MA, Bedell BJ, Beach TG, Sadowsky CH, Doraiswamy PM, Gamez J, Sabbagh MN, Fleisher AS, Schaerf F, Waseem M, Pontecorvo MJ, Hefti FF, Skovronsky DM, AV45-A07 Study Group: Phase III trial results for the amyoid PET imaging agent Florbetapir F 18 (18FAV-45): imaging to histopathologic correlations in an end-of-life human subject study. Alzheimer's Dementia 2010, 6:S71.

28. Rowe CC, Ackerman U, Browne W, Mulligan R, Pike KL, O'Keefe G, TochonDanguy H, Chan G, Berlangieri SU, Jones G, Dickinson-Rowe KL, Kung HP, Zhang W, Kung MP, Skovronsky D, Dyrks T, Holl G, Krause S, Friebe M, Lehman L, Lindemann S, Dinkelborg LM, Masters CL, Villemagne VL: Imaging of amyloid $\beta$ in Alzheimer's disease with ${ }^{18} \mathrm{~F}-\mathrm{BAY} 94-9172$, a novel PET tracer: proof of mechanism. Lancet Neurol 2008, 7:129-135.

29. Nelissen N, Van Laere K, Thurfiell L, Owenius R, Vandenbulcke M, Koole M, Bormans G, Brooks DJ, Vandenberghe R: Phase 1 study of the Pittsburgh Compound $B$ derivative ${ }^{18} \mathrm{~F}$-Flutemetamol in healthy volunteers and patients with probable Alzheimer disease. J Nucl Med 2009, 50:1251-1259.

30. Vandenberghe R, Van Laere K, Ivanoiu A, Salmon E, Bastin C, Triau E, Hasselbalch S, Law I, Andersen A, Korner A, Minthon L, tan Garraux G, Nelissen N, Bormans G, Buckley C, Owenius R, Thurfell L, Farrar G, Brooks DJ: ${ }^{18} \mathrm{~F}$-Flutemetamol amyloid imaging in Alzheimer disease and mild cognitive impairment: a phase 2 trial. Ann Neurol 2010, 68:319-329.

31. Ikonomovic MD, Klunk WE, Abrahamson EE, Mathis CA, Price JC, Tsopelas ND, Lopresti BJ, Ziolko S, Bi W, Paljug WR, Debnath ML, Hope CE, Isanski BA, Hamilton RL, DeKosky ST: Post-mortem correlates of in vivo PiB-PET amyloid imaging in a typical case of Alzheimer's disease. Brain 2008, 131:1630-1645.

32. Zhang W, Oya S, Kung MP, Hou C, Maier DL, Kung HF: F-18 Polyethyleneglycol stilbenes as PET imaging agents targeting Abeta aggregates in the brain. Nucl Med Biol 2005, 32:799-809.

33. Bacskai BJ, Frosch MP, Freeman SH, Raymond SB, Augustinack JC, Johnson KA, Irizarry MC, Klunk WE, Mathis CA, Dekosky ST, Greenberg SM, Hyman BT, Growdon JH: Molecular imaging with Pittsburgh Compound B confirmed at autopsy. Arch Neurol 2007, 64:431-434.

34. Hyman BT, Trojanowski JQ: Consensus recommendations for the postmortem diagnosis of Alzheimer disease from the National Institute on Aging and the Reagan Institute Working Group on diagnostic criteria for the neuropathological assessment of Alzheimer disease. J of Neuropathol Exp Neurol 1997, 56:1095-1097.

35. Kantarci K, Yang C, Schneider JA, Senjem ML, Reyes DA, Lowe VL, Barne LL, Aggarwal NT, Bennett DA, Smith GE, Petersen RC, Jack CR, Boevee BF: Ante mortem amyloid imaging and $\beta$-amyloid pathology in a case with dementia with Lewy bodies. Neurobiol Aging 2010 [Epub ahead of print].

36. Cairns NJ, Ikonomovic MD, Benzinger T, Storandt M, Fagan AF, Shah A, Schmidt RE, Perry A, Taylor Reinwald L, Carter D, Felton A, Holtzman DM, Mintun MA, Klunk WE, Morris JC: Absence of Pittsburgh Compound B detection of cerebral amyloid beta in a patient with clinical, cognitive, and cerebrospinal fluid markers of Alzheimer disease. Arch Neurol 2009, 66:1557-1562.

37. Mirra SS, Heyman A, McKeel D, Sumi SM, Crain BJ, Brownlee LM, Vogel FS, Hughes MS, van Belle G, Berg L and participating CERAD neuropathologists: The Consortium to Establish a Registry for Alzheimer's Disease (CERAD). Part II. Standardization of the neuropathologic assessment of Alzheimer's disease. Neurology 1991, 41:479-486.

38. Leinonen V, Alafuzoff I, Aalto S, Suotunen T, Savolainen S, Någren K, Tapiola T, Pirttilä T, Rinne J, Jääskeläinen JE, Soininen H, Rinne JO: Assessment of $\beta$-amyloid in a frontal cortical brain biopsy specimen and by positron emission tomography with carbon-11-labeled Pittsburgh compound B. Arch Neurol 2008, 10:1304-1309.

39. Delaère $P, H e Y$, Fayet $G$, Duyckaerts $C$, Hauw JJ: Beta A4 deposits are constant in the brain of the oldest old: an immunocytochemical study of 20 French centenarians. Neurobio/ Aging 1993, 14:191-194

40. Jagust WJ, Bandy D, Chen K, Foster NL, Landau SM, Mathis CM, Price JL, Reiman EM, Skovronsky DM, Koeppe RA, The Alzheimer's Disease Neuroimaging Initiative: The Alzheimer's Disease Neuroimaging Initiative positron emission tomography core. Alzheimer's Dement 2010, 6:221-229.

41. Jack CR, Knopman DS, Jagust WJ, Shaw LM, Aisen PS, Weiner MW, Petersen RC, Trojanowski JQ: Hypothetical model of dynamic biomarkers of the Alzheimer's pathological cascade. Lancet Neurol 2010 9:119-128.

42. Sperling RA, Dickerson BC, Pihlajamaki M, Vannini, P, LaViolette PS, Vitolo OV, Hedden T, Becker JA, Rentz DM, Selkoe DJ, Johnson KA: Functional alterations in memory networks in early Alzheimer's disease. Neuromol Med 2010, 12:27-43.

43. Rowe CC, Ellis KA, Rimajovae M, Bourgeat P, Pike KE, Jones G, Fripp J, TochonDanguya H, Morandeaug L, O'Keefe G, Price R, Raniga P, Robins P, Acosta O, Lenzo N, Szoekeh C, Salvadof O, Head R, Martins R, Masters CL, Ames D, Villemagne VL: Amyloid imaging results from the Australian Imaging, Biomarkers and Lifestyle (AIBL) study of aging. Neurobiol Aging 2010, 31:1275-1283

44. Hulette CM, Welsh-Bohmer KA, Murray MG, Saunders AM, Mash DC, Mclntyre LM. Neuropathological and neuropsychological changes in 'normal' aging: evidence for preclinical Alzheimer disease in cognitively normal individuals. J Neuropathol Exp Neurol 1998, 57:1168-1174. 
45. Knopman DS, Parisi JE, Salviati A, Floriach-Robert M, Boeve BF, Ivnik RJ, Smith GE, Dickson DW, Johnson KA, Petersen LE, McDonaldWC, Braak H, Petersen RC: Neuropathology of cognitively normal elderly. J Neuropathol Exp Neurol 2003, 62:1087-1095.

46. Price JL, Morris JC: Tangles and plaques in nondemented aging and "preclinical" Alzheimer's disease. Ann Neurol 1999, 45:358-368.

47. Bennett DA, Schneider JA, Bienias JL, Evans DA, Wilson RS: Mild cognitive impairment is related to Alzheimer's disease pathology and cerebral infarctions. Neurology 2005, 64:834-841.

48. Petersen RC, Parisi JE, Dickson DW, Johnson KA, Knopman DS, Boeve BF, Jicha BA, Ivnik RJ, Smith GE, Tangalos EG, Braak H, Kokmen E: Neuropathologic features of amnestic mild cognitive impairment. Arch Neurol 2006, 63:665-672.

49. Fagan AM, Mintun MA, Shah AR, Aldea P, Roe CM, Mach RH, Marcus D, Morris JC, Holtzman DM: Cerebrospinal fluid tau and ptau181 increase with cortical amyloid deposition in cognitively normal individuals: Implications for future clinical trials of Alzheimer's disease. Mol Med 2009, 1:371-380.

50. De Meyer G, Shapiro F, Vanderstichele H, Vanmechelen E, Engelborghs S, De Deyn PP, Coart E, Hansson O, Minthon L, Zetterberg H, Blennow K, Shaw L, Trojanowski JQ, for the Alzheimer's Disease Neuroimaging Initiative: Diagnosis-independent Alzheimer disease biomarker signature in cognitively normal elderly people. Arch Neurol 2010, 67:949-956.

51. Jack CR, Lowe VJ, Weigand SD, Wiste HJ,Senjem ML, Knopman DS, Shiung MM, Gunter JL, Boeve BF, Kemp BJ, Weiner M, Petersen RC; the Alzheimer's Disease Neuroimaging Initiative: Serial PIB and MRI in normal, mild cognitive impairment and Alzheimer's disease: implications for sequence of pathological events in Alzheimer's disease. Brain 2009, 132:1355-1365.

52. Mintun MA, Larossa GN, Sheline YI, Dence CS, Lee SY, Mach RH, Klunk WE, Mathis CA, DeKosky ST, Morris JC: [11C]PIB in a nondemented population: potential antecedent marker of Alzheimer disease. Neurology 2006, 67:446-452.

53. Morris JC, Roe CM, Xiong C, Grant EA, Fagan AM, Goate AM, Mintun MA: APOE predicts $A \beta$ but not Tau Alzheimer's pathology in cognitively normal aging. Ann Neurol 2010, 67:122-131.

54. Jack CR, Lowe VJ, Senjem ML, Weigand SD, Kemp BJ, Shiung MM, Knopman DS, Boeve BF, Klunk WE, Mathis CA, Petersen RC: ${ }^{11} \mathrm{C}$ PiB and structural MRI provide complementary information in imaging of $A D$ and amnestic $\mathrm{MCl}$. Brain 2008, 131:665-680.

55. Pike KE, Savage G,Villemagne VL, NG S, Moss SA, Maruff P, Mathis CA, Klunk $W E$, Masters $C L$, Rowe CC: $\beta$-amyloid imaging and memory in nondemented individuals: evidence for preclinical Alzheimer's disease. Brain 2007, 130:2837-2844.

56. Okello A, Koivunen J, Edison P, Archer HA, Turkheimer FE, Nagren K, Bullock R, Walker Z, Kennedy A, Fox NC, Rossor MN, Rinne JO, Brooks DJ: Conversion of amyloid positive and negative $\mathrm{MCl}$ to $\mathrm{AD}$ over 3 years: An ${ }^{11} \mathrm{C}$-PIB PET study. Neurology 2009, 73:754-760.

57. Forsberg A, Engler H, Almkvist O, Blomquist $G$, Hagman $G$, Wall A, Ringheim A, Langstrome B, Nordberg A: PET imaging of amyloid deposition in patients with mild cognitive impairment. Neurobio/ Aging 2008, 29:1456-1465.

58. Ong K, Villemagne VL, Langdon N, Holl G, Reininger C, Putz B, Jones $G$, Mulligan R, Pejoska S, Rohde B, Masters CL, Rowe CC: Assessment of A $\beta$ deposition in mild cognitive impairment with $18 \mathrm{~F}$-Florbetaben. Alzheimer's Dementia 2010, 6:S26.

59. Sperling RS, Doraiswamy PM, Johnson K, Reiman EM, Sabbagh MN, Sadowsky $\mathrm{CH}$, Carpenter A, Clark CM, Flitter M, Pontecorvo MJ, Skovronsky DM: Florbetapir F $18\left({ }^{18} \mathrm{~F}-\mathrm{AV}-45\right)$ PET amyloid imaging predicts progression of cognitive impairment: a longitudinal clinical follow up study. Alzheimer's Dementia 2010, 6:S71

60. Braak H, Braak E: Evolution of the neuropathology of Alzheimer's disease. Acta Neurol Scand Suppl 1996, 165:3-12.

61. Rosenberg PB, Wong DF, Edell S, Ross J, Joshi AD, Brašić JR, Zhou Y, Raymont V, Kumar A, Ravert HT, Dannals RF, Pontecorvo MJ, Skovronsky DM, Lyketsos CG: Cognition and amyloid load in Alzheimer's imaged with florbetapir F $18\left({ }^{18} \mathrm{~F}-\mathrm{AV}-45\right)$ PET. Am J GerPsych, in press.

62. Storandt M, Mintun MA, Head D, Morris JC: Cognitive decline and brain volume loss as signatures of cerebral amyloid- $\beta$ peptide deposition identified with Pittsburgh Compound B. Arch Neurol 2009, 66:1476-1481.
63. Mormino EC, Kluth JT, Madison CM, Rabinovici GD, Baker SL, Miller BL, Koeppe RA, Mathis CA, Weiner MW, Jagust WJ, the Alzheimer's Disease Neuroimaging Initiative: Episodic memory loss is related to hippocampalmediated $\beta$-amyloid deposition in elderly subjects. Brain 2008, 132:1310-1323.

64. Rentz DM, Locascio JJ, Becker JA, Moran EK, Eng E, Buckner RL, Sperling RA, Johnson KA: Cognition, reserve, and amyloid deposition in normal aging. Ann Neurol 2010, 67:353-364.

65. Roe CM, Mintun MA, D'Angelo G, Xiong C, Grant EA, Morris JC: Alzheimer's and cognitive reserve: Education effect varies with [11C]PIB Uptake. Arch Neurol 2008, 65:1467-1471.

66. Park DC, Kennedy KM, Rodrigue KM, Rieck JR, Flicker B, Devous MD: Betaamyloid deposition is associated with decreased processing speed and working memory but not reasoning or episodic memory in a highly screened healthy lifespan sample. Program Number 803.1/11147. 2010 Neuroscience Meeting Planner. San Diego, CA: Society for Neuroscience, 2010. Online [http://www.sfn.org/skins/main/pdf/abstracts/am2010/poster_ presentations/PosterPresentation WedAM.pdf]

67. Resnick SM, Sojkova J, Zhou Y, An Y, Ye W, Holt DP, Dannals RF, Mathis CA, Klunk WE, Ferrucci L, Kraut MA, Wong DF: Longitudinal cognitive decline is associated with fibrillar amyloid-beta measured by [11C]PiB. Neurology 2010, 74:807-815.

68. Wolk DA, Price JC, Saxton JA, Snitz BE, James JA, Lopez OL, Aizenstein HJ, Cohen AD, Weissfeld LA, Mathis CA, Klunk WE, DeKosky ST: Amyloid imaging in mild cognitive impairment subtypes. Ann Neurol 2009 65:557-568.

69. Jack CR, Wiste HJ, Vemuri P, Weigand SD, Senjem ML, Zeng G, Bernstein MA, Gunter JL, Pankratz VS, Aisen PS, Weiner MW, Petersen RC, Shaw LM, Trojanowski JQ, Knopman DS; the Alzheimer's Disease Neuroimaging Initiative: Brain beta-amyloid measures and magnetic resonance imaging atrophy both predict time-to-progression from mild cognitive impairment to Alzheimer's disease. Brain 2010, 133:3336-3348.

70. Morris JC, Roe CM, Grant EA, Head D, Storandt M, Goate AM,. Fagan AM, Holtzman DM, Mintun MA: Pittsburgh compound B imaging and prediction of progression from cognitive normality to symptomatic Alzheimer disease. Arch Neurol 2009, 66:1469-1475.

71. Villemagne VL, Pike KE, Darby D, Maruff P, Savage G, Ng S, Ackermann U, Cowie TF, Currie J, Chan SG, Jones G, Tochon-Danguy H, O'Keefe G, Masters $C L$, Rowe $C C$ : $A \beta$ deposits in older non-demented individuals with cognitive decline are indicative of preclinical Alzheimer's disease. Neuropsychologia 2008, 46:1688-1697.

72. Sperling RA, Dickerson BC, Pihlajamaki M, Vannini P, LaViolette PS, Vitolo OV, Hedden T, Becker JA, Rentz DM, Selkoe DJ, Johnson KA: Functional alterations in memory networks in earlyAlzheimer's disease. Neuromol Med 2010, 12:27-43.

73. Walker Z, Jaros E, Walker RWH, Lee L, Costa DC, Livingston G, Ince PG, Perry R, McKeith I, Katona CLE: Dementia with Lewy bodies: a comparison of clinical diagnosis, FP-CIT single photon emission computed tomography imaging and autopsy. J Neuro/ Neurosurg Psychiatry 2007, 78:1176-1181.

74. Hefti FF, Kung HF, Kilbourn MR, Carpenter AP, Skovronsky DM: ${ }^{18} \mathrm{~F}-\mathrm{AV}-133$ : a selective VMAT2-binding radiopharmaceutical for PET imaging of dopaminergic neurons. PET Clin 2010, 5:75-82.

75. Okamura N, Villemagne VL, Drago J, Pejoska S, Dhamija RK, Mulligan RS, Ellis JR, Ackermann U, O'Keefe G, Jones G, Gong S, Tochon-Danguy H, Hughes A, Pontecorvo MJ, Kung HF, Skovronsky DM, Rowe CC: In vivo measurement of vesicular monoamine transporter type 2 density in Parkinson's disease with ${ }^{18} \mathrm{~F}-\mathrm{AV}$-133. J Nuc Med 2010, 51:223-228.

doi:10.1186/alzrt70

Cite this article as: Pontecorvo MJ, Mintun MA: PET amyloid imaging as a tool for early diagnosis and identifying patients at risk for progression to Alzheimer's disease. Alzheimer's Research \& Therapy 2011, 3:11. 